\title{
Preparation of $t$-Butyldimethylphosphine Borane and $t$-Butyldiethylphosphine Borane by Selective Grignard Reagent Substitution of Phosphorus Trichloride
}

\author{
Auston G. Butterfield, Matthew B. Prater, and Nathan S. Werner* \\ Department of Physical Science, Southern Utah University, Cedar City, Utah \\ Students: austonbutterfield@hotmail.com,matt222@gmail.com \\ Mentor:nathanwerner@suu.edu*
}

\begin{abstract}
The synthesis of differentially substituted trialkylphosphine boranes from the selective substitution reaction of Grignard reagents with phosphorus trichloride in a single reaction flask was studied. The reaction temperature, stoichiometric loading of the first equivalent of Grignard reagent and reaction time were found to be important for maximizing the yield and selectivity of the reaction. Reaction conditions were optimized to achieve maximum yield of $t$-butyldiethylphosphine borane. The optimized conditions were applied to the syntheses of $t$-butyldiethylphosphine borane and $t$-butyldimethylphosphine borane, which provided $60 \%$ and $62 \%$ isolated yields respectively. Products were characterized with mass spectrometry, infrared spectroscopy, ${ }^{1} \mathrm{H},{ }^{13} \mathrm{C}$, and ${ }^{31} \mathrm{P}$ nuclear magnetic resonance spectroscopy.
\end{abstract}

\section{KEYWORDS}

Synthesis; Trialkylphosphine; Grignard Reagent; Selective; Substitution Reaction; $t$-Butyldiethylphosphine Borane; t-Butyldimethylphosphine Borane; Phosphorus Trichloride

\section{INTRODUCTION}

The reactions of Grignard reagents with phosphorus trihalides have been known for over a century. ${ }^{1-3}$ Moreover, the alkylated phosphorus products of these reactions are useful as ligands in many transition metal-catalyzed transformations. ${ }^{3-8}$ Previous to this work, it has been common to isolate the alkyldichlorophosphine or purchase it from commercial sources before substituting the remaining two chlorides with alkyl nucleophiles. ${ }^{10-12}$ For example, $t$-butyldimethylphosphine borane can be prepared from $t$-butyldichlorophosphine and $\mathrm{MeMgBr}$ in $60 \%$ yield. ${ }^{13}$ However, general procedures for the selective one-pot substitution of different alkyl Grignard reagents with phosphorus trichloride to form differentially substituted trialkylphosphines remain unknown. ${ }^{14}$ This is despite the fact that this represents the most straightforward way to prepare differentially substituted trialkylphosphines from inexpensive phosphorus trichloride. Herein we report our studies on the synthesis of $t$-butyldimethylphosphine borane and $t$-butyldiethylphosphine borane by selective Grignard reagent substitution reactions with phosphorus trichloride.

Borane protected trialkylphosphines were used in this work because electron rich trialkylphosphines are reactive with oxygen which makes their handling difficult. Fortunately, borane can be used to protect the readily oxidizable phosphorus atom by simple Lewis base/Lewis acid complexation. ${ }^{16}$ This technique has multiple advantages: (1) the phosphine can be protected in situ by reaction with borane in tetrahydrofuran (THF), (2) the phosphine-borane adduct is stable to the exposure of ambient oxygen, silica gel chromatography, and aqueous acids; which enables the handling and purification of the phosphine-borane adducts, (3) the borane protecting group can be readily removed by reaction with a Lewis base ${ }^{17}$ or strong anhydrous acid. ${ }^{18,19}$

\section{RESULTS AND DISCUSSION}

Initial studies on the selective addition of Grignard reagents to $\mathrm{PCl}_{3} \mathbf{1}$ began with the reaction of $t-\mathrm{BuMgCl} 2$ and 1 (Scheme $\mathbf{1}$ ). The Grignard reagent $t-\mathrm{BuMgCl}$ was chosen because the preparation of $t-\mathrm{BuPCl}_{2}$ suggested that the large size of $t-\mathrm{BuMgCl}$ would allow for selectivity between the mono, di, and trisubstitution reaction. ${ }^{11}$ A second Grignard reagent was then added to substitute the remaining two chlorine atoms and the phosphorus atom was protected with borane prior to workup and analysis by gas chromatography-mass spectrometry (GC-MS). Preliminary experiments evaluated a variety of Grignard reagents as nucleophiles in the second substitution reaction. Grignard reagents with primary, secondary and tertiary sp ${ }^{3}$ hybridized C-Mg bonds, as well as 
$\mathrm{sp}^{2}$ hybridized $\mathrm{C}-\mathrm{Mg}$ bonds were evaluated. Of these initially evaluated Grignard reagents, only EtMgCl provided clean production of the desired $t$-butyldialkylphosphine $\mathbf{5}$. Therefore, $\mathrm{EtMgCl}$ was chosen as the second Grignard reagent for studies directed to optimize the yield of the selective substitution reaction.
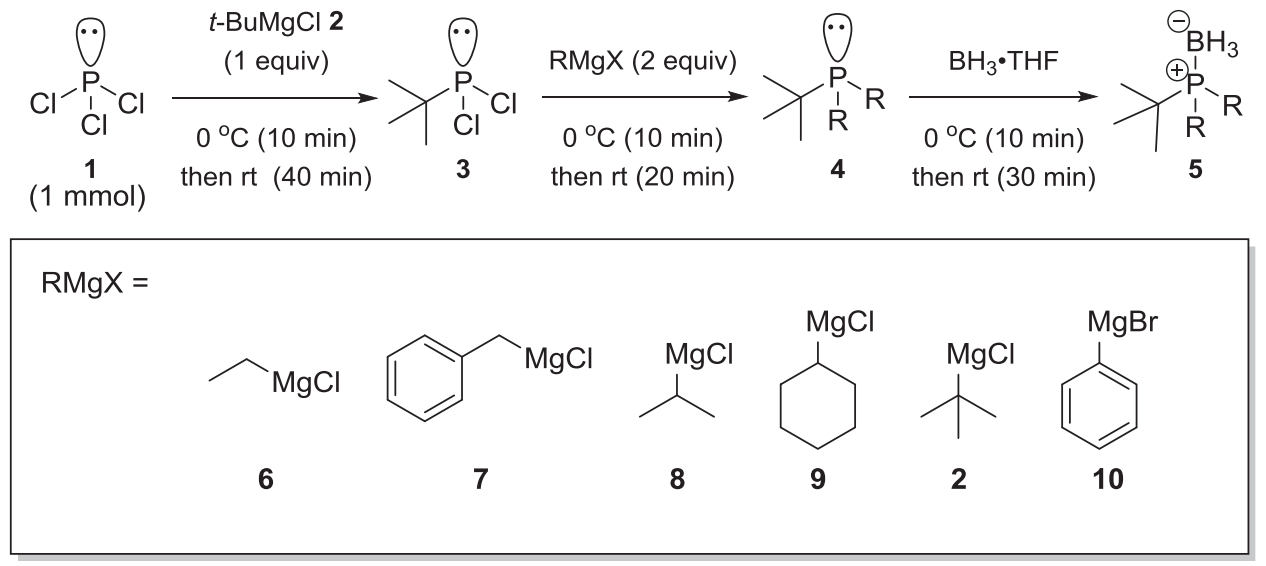

Scheme 1.

The selective substitution reaction of one equivalent of $t-\mathrm{BuMgCl}$ and two equivalents of $\mathrm{EtMgCl}^{6}$ with $\mathrm{PCl}_{3}$ was optimized by evaluating reagent equivalents and the incubation time between reagent additions (Table 1). In all experiments, reagents were added to the reaction mixture once it had been cooled to $0^{\circ} \mathrm{C}$ in an ice bath..$^{20}$ After each reagent addition, the reaction mixture was allowed to stir for $10 \mathrm{~min}$ at $0{ }^{\circ} \mathrm{C}$ before warming to room temperature for the time specified. The reaction mixture was again cooled to $0^{\circ} \mathrm{C}$ before the next reagent was added. An experiment following these standard conditions provided $88 \%$ of $t$-butyldiethylphosphine borane 11 by GC-MS analysis of the crude reaction mixture (entry 1). Allowing the reaction to immediately warm to room temperature only after the addition of $t-\mathrm{BuMgCl}$ provided $71 \%$ of $\mathbf{1 1}$ (entry 2). In addition, allowing reactions to stir for ten minutes at $0^{\circ} \mathrm{C}$ prior to warming to room temperature decreased the amount of $\mathbf{1 3}$ produced, which later proved to be inseparable from 11 via chromatography. These results suggest that the first substitution reaction time of 10 min at 0 ${ }^{\circ} \mathrm{C}$ is important to achieve selectivity for monoaddition. Next, the stoichiometric loading of $t$ - $\mathrm{BuMgCl}(1-1.25$ equiv) with respect to 1 was examined (compare entries 1, 3, and 4). The yield of 11 was found to be similar when 1.0 or 1.25 equiv of $t-\mathrm{BuMgCl}$ was used, however 1.0 equiv of $t-\mathrm{BuMgCl}$ produced less of the diaddition reaction product $14 .{ }^{5}$ The reaction times at room temperature after the addition of $t-\mathrm{BuMgCl}$ were then studied (entries 5-9). In these experiments, the yield of 11 increased only slightly from $88 \%$ to $90 \%$ as the reaction time was increased up to 40 minutes. However, at 60 minutes the yield of 11 began to decrease and production of $\mathbf{1 4}$ increased. The reaction times at room temperature after the addition of EtMgCl were also studied (entries 10-14). Unlike the reaction times associated with the addition of $t \mathrm{BuMgCl}$, reaction times of greater than 20 minutes after the addition of EtMgCl showed no significant change in the yield of $\mathbf{1 1}$. 


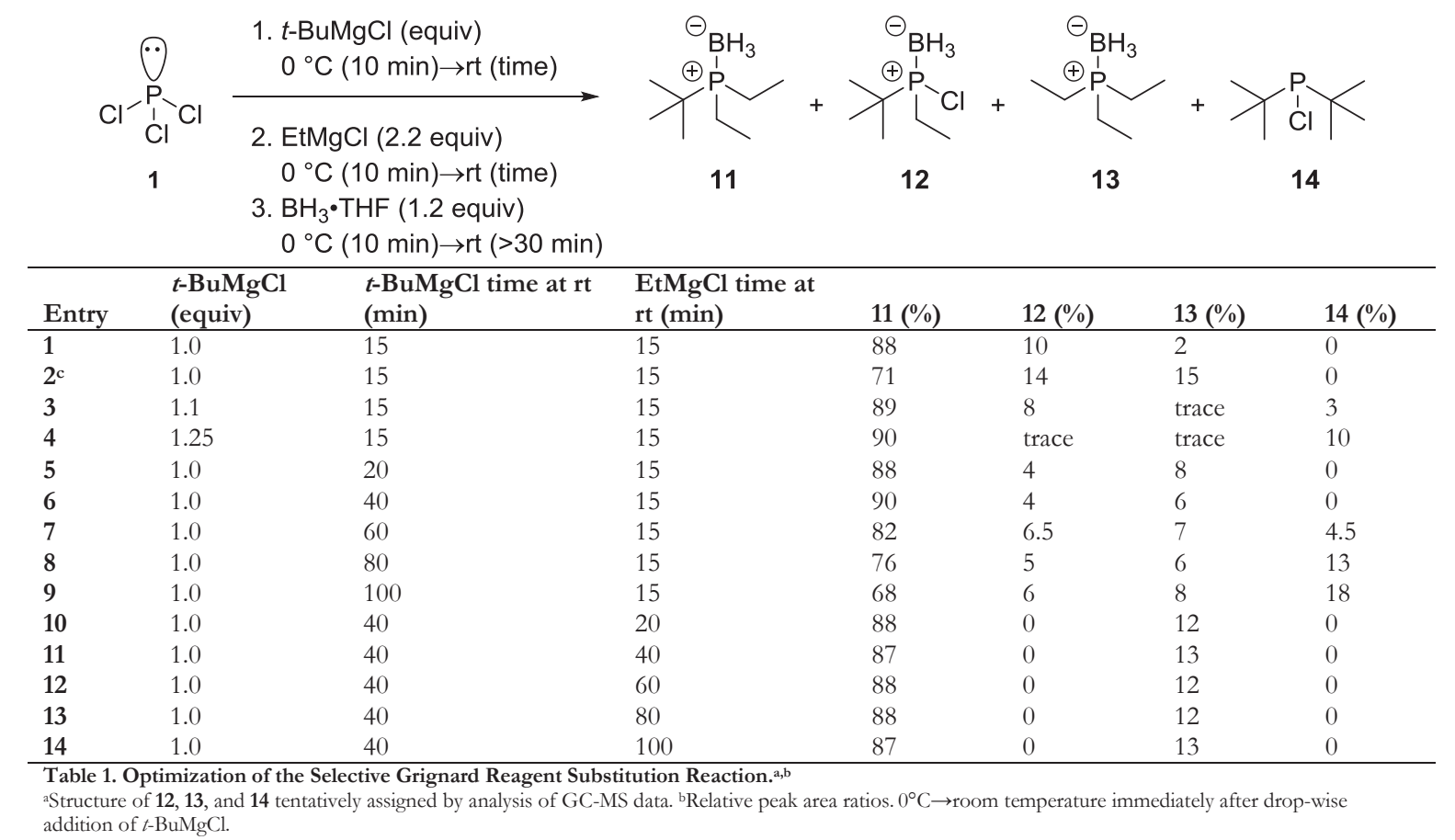

An additional set of experiments to evaluate Grignard reagent scope were performed using the previously optimized reaction conditions. In these experiments, $t$-butyldichlorophosphine was prepared in situ by reaction of $\mathrm{PCl}_{3}$ and $t-\mathrm{BuMgCl}$ at $0^{\circ} \mathrm{C}$ for 10 min and warming to room temperature and stirring an additional $40 \mathrm{~min}$. The reaction was cooled to $0^{\circ} \mathrm{C}$ and a Grignard reagent (2.0 equiv) from Figure 1 was then added drop-wise by syringe. The reaction was stirred for $10 \mathrm{~min}$ at $0^{\circ} \mathrm{C}$ before warming to room temperature and stirring an additional $20 \mathrm{~min}$. The reaction was cooled to $0^{\circ} \mathrm{C}$ and $\mathrm{BH}_{3} \cdot \mathrm{THF}$ was added drop-wise by syringe. The reaction was again stirred for $10 \mathrm{~min}$ at $0^{\circ} \mathrm{C}$ before warming to room temperature and stirring an additional $3 \mathrm{~h}$. In addition to $\mathrm{EtMgCl}, \mathrm{MeMgCl} 15$ was also found to provide clean production of the desired $t$-butyldialkylphosphine borane by GC-MS analysis of crude reaction aliquots under the optimized reaction conditions. The optimized reaction conditions were then applied to the $5 \mathrm{mmol}$ preparation of $t$-butyldiethylphosphine borane 11 and $t$-butyldimethylphosphine borane 16.

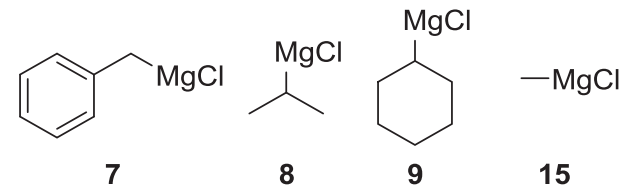

Figure 1. Grignard reagents evaluated under the optimized reaction conditions. 
Procedure for the Synthesis of t-Butyldiethylphosphine Borane (11)

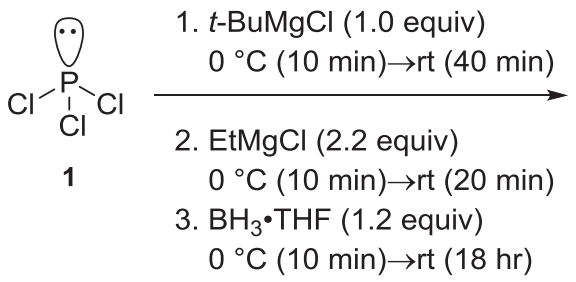

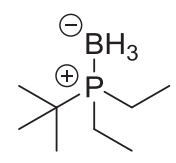

11

$60 \%$ isolated yield 4 reactions in one flask

To an oven dried, 50-mL, single neck, round-bottomed flask, containing a magnetic stir bar, capped with a septum that was bound with copper wire, and then evacuated and filled with argon $(\times 3)$ was added dry THF by syringe. The solvent was purged for $20 \mathrm{~min}$ with argon. The flask was cooled to $0^{\circ} \mathrm{C}$ using an ice bath, followed by the addition of $\mathrm{PCl}_{3}(436 \mu \mathrm{L}, 5 \mathrm{mmol})$ by syringe. $t-\mathrm{BuMgCl}\left([1.7], 2.94 \mathrm{~mL}, 1.0\right.$ equiv) was added drop-wise by syringe and allowed to stir at $0^{\circ} \mathrm{C}$ for $10 \mathrm{~min}$. The reaction was warmed to room temperature by removal from the cooling bath and stirred for $40 \mathrm{~min}$. The reaction was cooled to $0^{\circ} \mathrm{C}$ and $\mathrm{EtMgCl}$ ([2.7], $4.07 \mathrm{~mL}, 2.2$ equiv) was added drop-wise by syringe. The reaction was allowed to stir at $0^{\circ} \mathrm{C}$ for 10 min, warmed to room temperature, and stirred an additional $20 \mathrm{~min}$. The mixture was cooled to $0^{\circ} \mathrm{C}$ and $\mathrm{BH}_{3} \cdot \mathrm{THF}([1.0], 6.0 \mathrm{~mL}, 1.2$ equiv) was added drop-wise by syringe. The reaction was allowed to stir at $0^{\circ} \mathrm{C}$ for $10 \mathrm{~min}$, warmed to room temperature, and stirred at least $30 \mathrm{~min}$. The mixture was quenched by slow addition to a stirred solution of $1 \mathrm{M} \mathrm{HCl}(60 \mathrm{~mL})$ at $0^{\circ} \mathrm{C}$. The resulting mixture was extracted with EtOAc $(3 \times 10 \mathrm{~mL})$. The combined organic extracts were washed with brine $(3 \times 20 \mathrm{~mL})$, and dried over anhydrous $\mathrm{Na}_{2} \mathrm{SO}_{4}$. The solution was concentrated by rotary evaporation at $50^{\circ} \mathrm{C}$ and 140 torr. Residual solvent was further removed under vacuum at 2 torr for $20 \mathrm{~min}$.

The crude product was purified by silica gel column chromatography. The column was prepared using $40 \mathrm{~g}$ of silica gel suspended in hexane. The product was loaded neat and the flask was rinsed with minimal dichloromethane. An eluent consisting of a concentration gradient of $100 \mathrm{~mL}$ hexane, $100 \mathrm{~mL} \mathrm{1 \%} \mathrm{EtOAc/hexane,} \mathrm{and} 100 \mathrm{~mL} \%$ EtOAc/hexane was used to elute the product. Fractions (2-3 $\mathrm{mL}$ each) were collected and analyzed by thin-layer chromatography. Fractions containing the desired product were combined and concentrated as described above to provide $480 \mathrm{mg}(60 \%)$ of $\mathbf{1 1}$ as a white, crystalline solid (Scheme 2). The product was stable to exposure to ambient oxygen and was stored in a refrigerator for weeks with no discernible change in purity or reactivity.

Data for t-Butyldietbylphosphine Borane (11)

mp: $\quad 42.7-43.5^{\circ} \mathrm{C}$

1 $\mathrm{H} \mathrm{NMR}: \quad\left(400 \mathrm{MHz}, \mathrm{CDCl}_{3}\right)$

$1.62\left(\mathrm{~m}, 4 \mathrm{H}, \mathrm{C} \underline{\boldsymbol{H}}_{2} \mathrm{Me}\right), 1.16\left(\mathrm{~d}, J=12.9,9 \mathrm{H}, \mathrm{C}\left(\underline{\mathrm{C}}_{3}\right)_{3}\right), 1.18\left(\mathrm{dt}, J=15.0,7.5,6 \mathrm{H}, \mathrm{CH}_{2} \underline{\mathrm{C}}_{3}\right), 0.46(\mathrm{td}, J=$ 94.7, 14.3, $\left.3 \mathrm{H}, \underline{\boldsymbol{H}}_{3} \mathrm{~B}\right)$.

13. $\mathrm{C} M R: \quad\left(130 \mathrm{MHz}, \mathrm{CDCl}_{3}\right)$

$28.1\left(\mathrm{~d}, J=33.1, \underline{\boldsymbol{C}}\left(\mathrm{CH}_{3}\right)_{3}\right), 25.7\left(\mathrm{~d}, J=1.4, \underline{\mathrm{C}}\left(\underline{\boldsymbol{C}} \mathrm{H}_{3}\right)_{3}\right), 13.2\left(\mathrm{~d}, J=32.7, \underline{\boldsymbol{C}} \mathrm{H}_{2} \mathrm{CH}_{3}\right), 8.06\left(\mathrm{~d}, J=1.9, \mathrm{CH}_{2} \underline{\boldsymbol{C}} \mathrm{H}_{3}\right)$

31P NMR: $\quad\left(162 \mathrm{MHz}, \mathrm{CDCl}_{3}\right)$

$33.7(\mathrm{q}, J=62.2)$.

IR: $\quad$ (neat)

2974 (w), 2944 (w), 2882 (w), 2373 (w), 2339 (w), 2317 (w), 2270 (w), 2252 (w), 1466 (w), 1409 (w), 1367 (w), 1273 (w), 1254 (w), 1203 (w), 1132 (w), 1076 (w), 1064 (w), 1043 (w), 1031 (w), 1020 (w), 940 (w), 822 (w), 774 (m), $751(\mathrm{w}), 709(\mathrm{w})$.

MS: $\quad($ EI, $70 \mathrm{eV})$

$159\left([\mathrm{M}-\mathrm{H}]^{+}, 8\right), 155(10), 146\left(\left[\mathrm{M}-\mathrm{BH}_{3}\right]^{+}, 100\right), 130$ (3), 116 (9), $102\left([\mathrm{M}-t \text {-butyl }]^{+}, 9\right), 90\left(\left[\mathrm{M}-\mathrm{BH}_{3}, t \text {-butyl }\right]^{+}\right.$, 98), 74 ([M-t-butyl, ethyl $\left.]^{+}, 16\right), 69$ (5), 62 ([M-BH 3 ,-butyl, ethyl $]^{+}$, 41), 57 (65), 53 (2).

TLC: $\quad R_{f} 0.43\left(95: 5\right.$ hexane/ethyl acetate) [silica gel, aqueous $\mathrm{KMnO}_{4}$ ] 
Procedure for the Synthesis of t-Butyldimethylphosphine Borane (16)
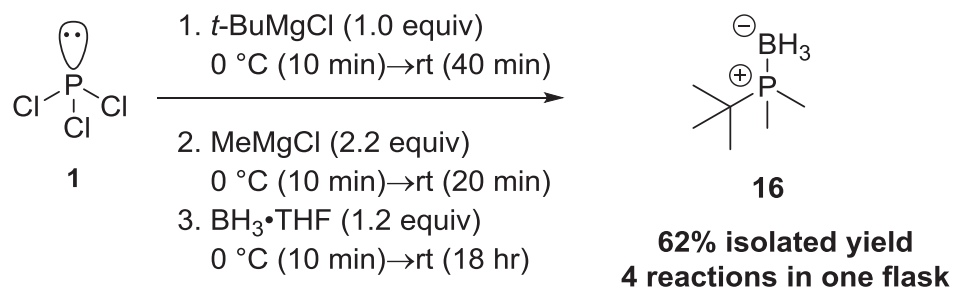

To an oven dried, 50-mL, single neck, round-bottomed flask, containing a magnetic stir bar, capped with a septum that was bound with copper wire, and then evacuated and filled with argon $(\times 3)$ was added dry THF by syringe. The solvent was purged for 20 min with argon. The flask was cooled to $0^{\circ} \mathrm{C}$ using an ice bath, followed by the addition of $\mathrm{PCl}_{3}(436 \mu \mathrm{L}, 5 \mathrm{mmol})$ by syringe. $t-\mathrm{BuMgCl}\left([1.7], 2.94 \mathrm{~mL}, 1.0\right.$ equiv) was added drop-wise by syringe and allowed to stir at $0^{\circ} \mathrm{C}$ for $10 \mathrm{~min}$. The reaction was warmed to room temperature by removal from the cooling bath and stirred for $40 \mathrm{~min}$. The reaction was cooled to $0^{\circ} \mathrm{C}$ and $\mathrm{MeMgCl}$ ([3.0], $3.67 \mathrm{~mL}, 2.2$ equiv) was added drop-wise by syringe. The reaction was allowed to stir at $0^{\circ} \mathrm{C}$ for 10 min, warmed to room temperature, and stirred an additional $20 \mathrm{~min}$. The mixture was cooled to $0^{\circ} \mathrm{C}$ and $\mathrm{BH}_{3} \cdot \mathrm{THF}(1.2$ equiv.) was added drop-wise by syringe. The reaction was allowed to stir at $0^{\circ} \mathrm{C}$ for $10 \mathrm{~min}$, warmed to room temperature, and stirred at least 30 min. The mixture was quenched by slow addition to a stirred solution of $1 \mathrm{M} \mathrm{HCl}(60 \mathrm{~mL})$ at $0^{\circ} \mathrm{C}$. The resulting mixture was extracted with $\mathrm{Et}_{2} \mathrm{O}(3 \times 10 \mathrm{~mL})$. The combined organic extracts were washed with brine $(3 \times 20 \mathrm{~mL})$, and dried over anhydrous $\mathrm{Na}_{2} \mathrm{SO}_{4}$. Et $\mathrm{E}_{2} \mathrm{O}$ was removed by rotary evaporation at $35^{\circ} \mathrm{C}$ and 200 torr. Residual solvent was further removed under vacuum at 2 torr for $20 \mathrm{~min}$.

The crude product was purified by column chromatography. The column was prepared using $40 \mathrm{~g}$ of silica gel suspended in hexane. The product was loaded neat and the flask was rinsed with minimal dichloromethane. An eluent consisting of a

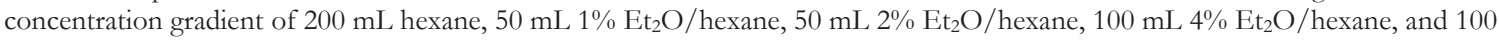
$\mathrm{mL} 6 \% \mathrm{Et}_{2} \mathrm{O} /$ hexane was used to elute the product. Fractions $(2-3 \mathrm{~mL}$ each) were collected and analyzed by thin-layer chromatography. Fractions found to contain the desired product were combined and concentrated as described above to provide $411 \mathrm{mg}(62 \%)$ of $\mathbf{1 6}$ as a white, crystalline solid (Scheme 3). The product was stable to exposure to ambient oxygen and was stored in a refrigerator for weeks with no discernible change in purity or reactivity.

Data for t-Butyldimethylphosphine Borane (16)

\begin{tabular}{|c|c|}
\hline \multirow{3}{*}{$\begin{array}{l}\underline{\mathrm{mp}:} \\
\underline{{ }^{1} \mathrm{H} \mathrm{NMR}:}\end{array}$} & $160.5-161.0^{\circ} \mathrm{C}$ \\
\hline & $\left(400 \mathrm{MHz}, \mathrm{CDCl}_{3}\right)$ \\
\hline & $1.24\left(\mathrm{~d}, J=9.9,6 \mathrm{H}, \mathrm{C} \underline{\boldsymbol{H}}_{3}\right) 1.17\left(\mathrm{~d}, J=13.5,9 \mathrm{H}, \mathrm{C}\left(\mathrm{C} \underline{\boldsymbol{H}}_{3}\right)_{3}\right) 0.5\left(\mathrm{qd} J=95.3,15.4,3 \mathrm{H}, \underline{\boldsymbol{H}}_{3} \mathrm{~B}\right)$ \\
\hline 13C NMR: & $\left(130 \mathrm{MHz}, \mathrm{CDCl}_{3}\right)$ \\
\hline 31P NMR: & $\begin{array}{l}26.65\left(\mathrm{~d}, J=35.09,1 \mathrm{C}, \underline{\boldsymbol{C}}\left(\mathrm{CH}_{3}\right)_{3}\right) 24.77\left(\mathrm{~d}, J=2.45,3 \mathrm{C}, \mathrm{C}\left(\underline{\boldsymbol{C H}}_{3}\right)_{3}\right) 7.30\left(\mathrm{~d} J=35.97,2 \mathrm{C}, \underline{\boldsymbol{C}} \mathrm{H}_{3}\right) \\
\left(162 \mathrm{MHz}, \mathrm{CDCl}_{3}\right)\end{array}$ \\
\hline & $20.3(\mathrm{q}, J=38 \mathrm{~Hz})$ \\
\hline IR: & heat) \\
\hline MS: & $\begin{array}{l}2965(\mathrm{w}) .2869(\mathrm{w}), 2376(\mathrm{~m}), 2256(\mathrm{w}), 1474(\mathrm{w}), 1463(\mathrm{w}), 1422(\mathrm{w}), 1290(\mathrm{w}), 1137(\mathrm{w}), 1068(\mathrm{w}), 1018(\mathrm{w}), \\
942(\mathrm{w}), 918(\mathrm{w}), 851(\mathrm{w}), 820(\mathrm{w}), 756(\mathrm{w}) .\end{array}$ \\
\hline & $\begin{array}{l}131([\mathrm{M}-\mathrm{H}], 12) .118\left(\left[\mathrm{M}-\mathrm{BH}_{3}\right], 100\right), 88 \text { ([M- } \mathrm{BH}_{3} \text {, methyl, methyl, 19), } 74 \text { ([M-t-butyl, H], 24), } 62 \text { (68), } 57 \\
\text { (50). }\end{array}$ \\
\hline TLC: & 0.20 (97:3 hexanes/diethyl ether) [silica gel, aqueous $\mathrm{KMnO}_{4}$ ] \\
\hline
\end{tabular}




\section{CONCLUSIONS}

The $t$-butyldialkylphosphine boranes, $t$-butyldiethylphosphine borane and $t$-butyldimethylphosphine borane, were prepared by selective Grignard substitution reaction of $\mathrm{PCl}_{3}$. The highlights of this method include the use of inexpensive $\mathrm{PCl}_{3}$ and a one-pot experimental procedure. Reaction temperature and time were found to be important for maximizing the yield and selectivity of the reaction. A stoichiometric loading of 1 equivalent of $t-\mathrm{BuMgCl}$ was found to be optimal. The optimized reaction conditions were demonstrated in the $5 \mathrm{mmol}$ preparation of $t$-butyldiethylphosphine borane and $t$-butyldimethylphosphine borane in $60 \%$ and $62 \%$ yields respectfully. We currently work to transform the phosphine boranes into phosphonium tetrafluoroborate salts and use them in transition metal-catalyzed reactions.

\section{ACKNOWLEDGEMENTS}

We are grateful to Southern Utah University for a Faculty Scholarly Support Fund Grant (N.S.W.), a Walter Maxwell Gibson Research Fellowship (A.G.B. \& M.B.P.), and a L.S. and Aline W. Skaggs Research Grant (M.B.P.) for the generous support of this work.

\section{REFERENCES}

1. Auger, V., Billy (1904) Action des solutions organomagnesiennes sur les derives halogeses du phosphore de l'arsenic et de l'antimoine, B C R 139, 597-599.

2. Quin, L. D. (2000) A Guide to Organophosphorus Chemistry, 1st ed., pp 45-92, Wiley, New York.

3. Kharasch, M. S., Reinmuth, O. (1954) Grignard Reactions of Nonmetallic Substances, 1st ed., pp 1335-1345, Prentice-Hall, New York.

4. Simard-Mercier, J., Jiang, J. L., Ho, M. L., Flynn, A. B., Ogilvie, W. W. (2008) Multidimensional steric parameters in the analysis of asymmetric catalytic reactions, J Org Chem 73, 5899-5906.

5. Nishizawa, K., Ouchi, M., Sawamoto, M. (2013) Phosphine-ligand decoration toward active and robust iron catalysts in LRP, Macromolecules 46, 3342-3349.

6. Grim, S. (1982) Catalytic aspects of metal phosphine complexes. Organometallics 1, 1106-1107.

7. Brasse, C. C., Englert, U., Salzer, A.; Waffenschmidt, H., Wasserscheid, P. (2000) Ionic phosphine ligands with cobaltocenium Backbone: novel ligands for the highly selective, biphasic, rhodium-catalyzed hydroformylation of 1-octene in ionic liquids, Organometallics 19, 3818-3823.

8. Simhai, N., Iverson, C. N., Edelbach, B. L., Jones, W. D. (2001) Formation of phenylene oligomers using platinum-phosphine complexes, Organometallics 20, 2759-2766.

9. Doherty, S., Knight, J. G., Ward, N. A. B., Bittner, D. M., Wills, C., McFarlane, W., Clegg, W., Harrington, R. W. (2013) Electron-rich trialkyl-type dihydro-KITPHOS monophosphines: efficient ligands for palladium-catalyzed Suzuki-Miyaura crosscoupling. Comparison with their biaryl-like KITPHOS monophosphine counterparts, Organometallics 32, 1773-1788.

10. McGrath, M. J., O’Brien, P. (2005) Catalytic asymmetric deprotonation using a ligand exchange approach, J Am Chem Soc 127, 16378-16379.

11. Rex E. Murray, Rex E. (May 26, 1987) Process for the preparation of bulky alkyldiarylphosphines and unsymmetrical aryldialkyl phosphines, Patent US 4,668,823.

12. Romanenko, V. D., Sanchez, M., Lamande, L. (1995) Comprehensive Organic Functional Group Transformations, Vol. 6, (Katritzky, A. R.; Meth-Cohn, O., Rees, C. W., Gilchrist, T. L., Ed.) $1^{\text {st }}$ ed., pp 689, Elsevier, New York.

13. Carbone, G., O’Brien, P., Hilmersson, G. (2010) Asymmetric deprotonation using $s$-BuLi or $i$-PrLi and chiral diamines in THF: the diamine matters, J Am Chem Soc 132, 15445-15450.

14. We are aware of a single report that describes the unoptimized synthesis of $t$-butyldimethylphosphine borane by selective Grignard reagent substitution reaction: Imamoto, T., Watanabe, J. Wada, Y., Masuda, H., Yamada, H., Tsuruta, H., Matsukawa, S., Yamaguchi, K. (1998) P-Chiral bis(trialkylphosphine) ligands and their use in highly enantioselective hydrogenation reactions, J Am Chem Soc 120, 1635-1636.

15. Hosein, A. I., Le Goff, X. F., Ricard, L., Caffyn, A. J. M. (2011) Reaction of perfluoroalkyl grignard reagents with phosphorus trihalides: a new route to perfluoroalkyl-phosphonous and -phosphonic acids, Inorg Chem 50, 1484-1490.

16. Staubitz, A., Robertson, A. P. M., Sloan, M. E., Manners, I. (2010) Amine- and phosphine-borane adducts: new interest in old molecules, Chem Rev 110, 4023-4078.

17. Taylor, N., Lloyd-Jones, G. C. (2015) Mechanism of phosphine borane deprotection with amines: the effects of phosphine, solvent and amine on rate and efficiency, Chem Eur J 21, 5423-5428.

18. Denmark, S. E.; Werner, N. S. (2011) $\gamma$-Selective cross-coupling of allylic silanolate salts with aromatic bromides using trialkylphosphonium tetrafluoroborate salts prepared directly from phosphine-borane adducts, Org Lett 13, 4596-4599. 
19. McKinstry, L., Overberg, J. J., Soubra-Ghaoui, C., Walsh, D. S., Robins, K. A., Toto, T. T., Toto, J. L. (2000) Acid mediated phosphine-borane decomplexation: a model for characterizing short-lived intermediates with Experimental and ab initio NMR data, J Org Chem 65, 2261-2263.

20. Silverman, G. S. (1996) Handbook of Grignard Reagents, (Silverman, G.S., Ed.) 1st ed., pp 307-354, Marcel Dekker, Inc., New York.

\section{ABOUT THE STUDENT AUTHORS}

Auston Butterfield graduated from Southern Utah University in 2015 with a B.S. degree in chemistry with an emphasis in healthcare and a minor in biology. While at SUU, Auston was the recipient of the Walter Maxwell Gibson Research Fellowship. He aspires to treat patients as a healthcare professional.

Matthew Prater graduated Magna Cum Laude from Southern Utah University in 2015 with a B.S. degree in chemistry with an emphasis in professional chemistry. While at SUU, Matthew was the recipient of the Walter Maxwell Gibson Research Fellowship, and the L.S. and Aline W. Skaggs Research Grant. He currently pursues a graduate degree in chemistry at the University of Utah.

\section{PRESS SUMMARY}

Trialkylphosphines are commonly used as ligands in the transition metal-catalyzed reactions that produce a number of fine chemicals and pharmaceuticals. These reactions often require tuning of the catalyst by subtle variation in the ligand structure to maximize yield and selectivity. This work describes the discovery and optimization of an efficient synthesis of

$t$-butyldimethylphosphine and $t$-butyldiethylphosphine, protected as their borane adducts, by a one-pot, selective Grignard reagent substitution reaction of inexpensive phosphorus trichloride. 